Molecular Characterization of Moroccan Fig Germplasm Using Intersimple Sequence Repeat and Simple Sequence Repeat Markers To Establish A Reference Collection

\author{
B. Khadari ${ }^{1}$ \\ Conservatoire Botanique National Méditerranéen de Porquerolles (CBNMP), \\ Parc National de Port-Cros, Castel Ste Claire, F 83418 Hyères cedex, France \\ A. Oukabli \\ INRA, Programme Arboriculture Fruitière, BP 578, Meknès Morocco
}

\author{
M. Ater \\ Ecologie et Biologie des Populations, Faculté des Sciences de Tétouan, B.P \\ 2062, M'hannech II Tétouan, Morocco
}

\section{A. Mamouni}

INRA, Programme Arboriculture Fruitière, BP 578, Meknès Morocco

\section{J.P. Roger}

Conservatoire Botanique National Méditerranéen de Porquerolles (CBNMP), Parc National de Port-Cros, Castel Ste Claire, F 83418 Hyères cedex, France

\author{
F. Kjellberg \\ Centre d'Ecologie Fonctionnelle et Evolutive, CNRS, 1919 route de Mende \\ 34293 Montpellier Cedex 5, France
}

Additional index words. Ficus carica L., ISSR, intersimple sequence repeats, SSR, simple sequence repeats, molecular characterization, genetic relationships, reference genotype

\begin{abstract}
A study was conducted to identify genotypes present in a Moroccan fig germplasm collection and provide the first database for a reference collection in northern Morocco. In total, 75 fig samples were analyzed using 8 intersimple sequence repeat primers and 6 simple sequence repeat loci. From these samples, we identified 72 fig genotypes. In genetically heterogeneous cultivars, genotypes under the same denomination were distinguished by both molecular markers and pomological traits. Molecular analysis was used to classify the germplasm into 46 well-defined cultivars and 6 caprifig trees. The remaining genotypes were not clearly identified due to three cases of mislabeling and four cases of homonymy. No evidence was found for the occurrence of geographically widespread genotypes.
\end{abstract}

Common fig, Ficus carica L., is one of the most ancient cultivated Mediterranean fruit (Zohary and Hopf, 2000). In northern Morocco, fig cultivars are highly diversified and provide a large array of genotypes (Oukabli et al., 2003). However, due to numerous cases of synonymy (several denominations for the same genotype) and homonymy (several genotypes

Received for publication 5 Aug. 2003. Accepted for publication 17 Mar. 2004. We thank I. Hochu and S. Santoni for technical support, M. Lahlou for tending the fig collection, and F. Boillot for his encouragement. We also thank F. Dosba and I.J. Hormaza for comments on the manuscript. The work was supported by funding from the BRG (Bureau des Ressources Génétiques, Paris) and by French-Moroccan cooperation program (PRAD 00-12).

${ }^{1}$ To whom correspondence should be addressed. Current address: UMR 1098 Biologie du Développement des Espèces Pérennes Cultivées (BEPC), Bat. 33, INRA, 2, place Viala, 34060 Montpellier cedex 1, France; e-mail khadari@ensam.inra.fr. under the same denomination), pomological characterization is insufficient to establish reference genotypes for fig breeding programs in the region. Molecular markers are needed to accurately identify fig genotypes and define a complete reference collection.

Isozymes were the first genetic markers used in genotype fingerprinting and have been applied in several fruit species including fig (Chessa et al., 1998; Elisiario et al., 1998; Uzun et al., 2003; Valizadeh et al., 1977). However, their usefulness has been limited due to the small number of isozyme systems available, the low level of polymorphism obtained, and the influence of environmental factors. The emergence of new polymerase chain reaction (PCR)-based molecular markers, such as randomly amplified polymorphic DNA (RAPD), amplified fragment-length polymorphisms (AFLPs), and simple sequence repeats (SSR), has created the opportunity for fine-scale genetic characterization of germplasm collections because they are highly polymorphic and are not readily influenced by environmental conditions (Geuna et al., 2003; Hokanson et al., 2001; Oraguzie et al., 2001; see also review by Wünsch and Hormaza, 2002). RAPD markers have been previously used for cultivar characterization in fig (De Masi et al., 2003; Elisiario et al., 1998; Khadari et al., 1995), but because of the use of arbitrary short sequences as primers and the relatively low annealing temperature, these markers cannot be exchanged among laboratories according to standardized protocols (Jones et al., 1997). To overcome this limitation, we previously compared data obtained by RAPD, intersimple sequence repeat (ISSR), and SSR analyses of 30 fig cultivars and showed that SSR and ISSR markers are complementary tools for a reliable fig characterization (Khadari et al., 2003c).

In the present study, ISSR and SSR markers were used to characterize local accessions in a Moroccan fig collection and provide a molecular database for fig breeding.

\section{Material and Methods}

Plant material. A Moroccan fig collection located at the Ain Taoujdate experimental station (INRA Meknès, Morocco) was used for study. The collection contained 72 local accessions and consisted of 54 cultivars and 8 caprifig (male) trees collected from northern Morocco and Algeria (Table 1). We defined an accession as one or several fig trees under the same denomination and registration number. In some cases, several accessions were classified under the same denomination (e.g., see 'Bioudi' denomination in Table 1). Molecular characterization was performed on one tree per accession except for three accessions, 'Abiarous' (65-3015), 'Bouankirh' (98-2397) and 'El Khal' (84-2283), in which two trees were analysed because distinct pomological traits were noted among trees within these accessions.

Molecular analyses. DNA was extracted from $100 \mathrm{mg}$ of frozen leaf material using the Dneasy Plant Mini Kit (Qiagen) following manufacturer recommendations with the exception that $1 \%$ polyvinylpyrrolidone (PVP 40000 ) was added to the AP1 buffer.

For ISSR analysis, four previously selected primers (IMA5, IMA8, IMA9, and IMA12; Table 2; Khadari et al., 2003c) and four new primers were used (IMA303, IMA834, UBC818, and UBC841; Table2). Following a test for polymorphism and for consistent and reproducible DNA amplification on five fig cultivars, these new primers were selected from seven primers obtained from MGW. Reproducibility in ISSR patterns was verified by three different DNA amplifications from a set of 10 accessions. The PCR amplification was performed in $10 \mathrm{mM}$ Tris- $\mathrm{HCl}(\mathrm{pH} 9.0)$, $50 \mathrm{~mm} \mathrm{KCl}, 1.5 \mathrm{~mm} \mathrm{MgCl} \mathrm{g}_{2} 0.1 \%$ TritonX100, $0.02 \%$ gelatin, with $0.2 \mathrm{mM}$ of each dNTP, 10 pmol of primer, 2 units of Taq DNA polymerase (Appligene-Oncor), and $50 \mathrm{ng}$ of DNA in a final volume of $25 \mu \mathrm{L}$. Amplifications were carried out in a 96-well thermocycler (model PTC100;MJ Research) using the following conditions: initial denaturation at $94{ }^{\circ} \mathrm{C}$ for 5 
Table 1. List of fig accessions analyzed.

\begin{tabular}{|c|c|c|c|}
\hline Denomination & Accession & Denomination & Accession \\
\hline Abiarous $^{\mathrm{zx}}$ & $65-3015$ (trees 9-8 and 9-9) & Hafer Jmel* & $58-2253$ \\
\hline Aboucharchaou $^{\mathrm{x} *}$ & $71-2395$ & Ham Rham* & $91-2866$ \\
\hline Abrouki* & $90-2221$ & Hamra & $\begin{array}{l}22-2225,35-2588, \\
86-2252\end{array}$ \\
\hline Ahra* & $63-2870$ & Hayoul* & $83-2250$ \\
\hline Aicha Moussa* & $57-2208$ & Hmidi* & $52-2250$ \\
\hline Amtalaa Aarch* & $87-2210$ & Jeblia* & $8-2288$ \\
\hline Aoud Elmaa* & $51-2217$ & & \\
\hline Aounq El Hmam* & $94-2876$ & Jeld Elhmar* & $89-2251$ \\
\hline Arouchi* & $85-2220$ & Kahoulia* & $32-2251$ \\
\hline Assel* & $92-2890$ & Mendar* & $56-2891$ \\
\hline Azendjar ${ }^{\mathrm{X} *}$ & $97-2113$ & M'hadeq* & $36-2239$ \\
\hline Azougouar* & $102-2116$ & Mtioui* & $50-2893$ \\
\hline Bioudi & $\begin{array}{l}1-2222,53-2878 \\
61-2255,64-2218 \\
66-2258\end{array}$ & Nabout* & $42-2893$ \\
\hline Beida* $^{*}$ & $11-2256$ & Noukali* & $31-2254$ \\
\hline Bouankirh $^{\mathrm{zx}}$ & $\begin{array}{l}\text { 98-2397 (trees 2-4 and 2-5) } \\
6-2214\end{array}$ & Ournakssi & $3-2280,5-2282$, \\
\hline Bourqui* & $48-2219$ & Reggoudi* & $16-2895$ \\
\hline Bousbati* & $2-2880$ & Rhazzali* & $46-2884$ \\
\hline Chaari & $95-2881,96-2587$ & Rhoudane & $24-2223,25-2227$ \\
\hline Chbaa Ou Rgoud* & $10-2249$ & Rhouli* & $82-2216$ \\
\hline El Har* & $59-2261$ & Sebti* & $4-2898$ \\
\hline El Hmiri* & $88-2224$ & Tameriout $\mathrm{t}^{\mathrm{x} *}$ & $67-2400$ \\
\hline $\mathrm{El} \mathrm{Khal}^{2}$ & $84-2283$ (trees $11-1$ and $11-3$ ) & Taranimt $\mathrm{x} *$ & $72-2399$ \\
\hline El quoti Lebied* & $49-2263$ & Tarlit* & $68-2398$ \\
\hline El quoti Lezreq* & $62-2883$ & $\operatorname{Amzin}^{y *}$ & --- \\
\hline Embar El Khal* & $21-2247$ & Doukar tardif $\mathrm{C}^{\mathrm{y} *}$ & --- \\
\hline Embar Lebied* & $7-2240$ & Tchellah $^{2 *}$ & --- \\
\hline Fassi* & $33-2267$ & Front d'eloued C11 & --- \\
\hline Ferquouch Jmel* & $13-2226$ & Front d'eloued C13 & --- \\
\hline Ferzaoui* & $93-2289$ & Kasbat Skhirat ${ }^{y *}$ & --- \\
\hline Filalia* & $34-2211$ & Ouzidane $\mathrm{C} 18^{\mathrm{y} *}$ & --- \\
\hline Ghadar El Arch* & $60-2213$ & Titent Scourt C17 ${ }^{y *}$ & --- \\
\hline Hafer El Brhel** & $44-$ & & \\
\hline
\end{tabular}

${ }^{2}$ Two trees were analyzed.

'Local caprifig clone.

${ }^{x}$ Algerian fig accessions.

*Well-defined cultivars and caprifigs.

min, followed by 35 cycles $\left(94{ }^{\circ} \mathrm{C} 30 \mathrm{~s}, 50\right.$ to $56{ }^{\circ} \mathrm{C} 1 \mathrm{~min}, 72{ }^{\circ} \mathrm{C} 1 \mathrm{~min}$ ) and a final extension at $72{ }^{\circ} \mathrm{C}$ for $7 \mathrm{~min}$. The amplification products were electrophoresed in 2\% agarose gels at 120 volts followed by staining with ethidium bromide and photographed on Polaroïd 667 film under ultra-violet light.

For SSR analysis, six loci out of eight developed by Khadari et al. (2001) were used (Table 2). Analysis was performed following a protocol described previously (Khadari et al., 2001).

Data analysis. For ISSR data, polymorphic bands were scored as present (1) or absent (0) based on products consistently amplified for each primer. We assumed each band position corresponded to a locus with two alleles. For SSR analysis, one or two bands were scored for each sample corresponding to homozygotic and heterozygotic individuals, respectively. Each polymorphic band was named by the primer code followed by the size of the amplified fragment in base pairs. ISSR and SSR markers were scored in a binary data matrix.

For each SSR loci, expected heterozygosity values were computed under the Hardy-Weinberg hypothesis according to the no-bias model (Nei, 1978) using Genetics 4.0 software (Belkhir et al., 1999). Significance of heterozygote deficiency was assessed using exact tests and Genepop 3.1b software (Raymond and Rousset, 1995). Probability of obtaining a given genotype was calculated under the hypothesis selection effect that would have occurred withina limited gene pool (Table 2). The 8 ISSR primers selected for polymorphism and for clear bands revealed a total of 37 markers ranging from 2 (primer IMA303) to 8 (primer IMA5), with a mean value of 4.6 markers per primer (Table 2). The highest frequencies were obtained for the UBC841-350ISSR marker(97\%) and the MFC4219 SSR allele (89\%). The lowest frequencies (about 1\%) were observed for 7 alleles belonging to the MFC2, MFC3, and MFC6 SSR loci and for the IMA303-900 ISSR marker.

Analysis of 75 fig samples using 75 polymorphic bands (38 SSR alleles and 37 ISSR bands) revealed 72 different molecular patterns. Of the genotype pairs, $98 \%$ were differentiated by 10 to 33 polymorphic bands; among 2,556 pairwise comparisons, only 5,6 , and 7 molecular profile pairs were distinguished by 1,2 , and 3 polymorphic bands, respectively (Fig. 1). The distribution of genetic differences in pairwise comparisons showed a bimodal distribution with a main mode centered at about 21 to 22 differences and a minor mode centered at about 2 to 3 differences (Fig. 1). Under the hypothesis of non-linkage between markers, the probability of obtaining a given molecular pattern was very low and ranged from $1.03 \times 10^{-12}$ for 'Filalia' (34-2211) to $2.87 \times 10^{-5}$ for 'Amzin' (caprifig 18-6). The use of ISSR markers alone enabled us to identify 72 molecular profiles, although the probability of obtaining a given pattern was much higher than when using all markers (ranging from $3.90 \times 10^{-7}$ to 0.060 ). In contrast, 18 genotype pairs were not distinguished using SSR markers alone.

The discriminating power of each ISSR primer or SSR locus used in this study varied from 0.944 to 0.516 (Table 2). The value obtained for the ISSR primer IMA303 was close to null because the markers were detected in only three genotypes. Discriminating power variation among primers or loci was due to either the number of markers per primer or the number of alleles per locus, and also to marker frequencies. Primer IMA5 was more discriminating than the MFC6 and MFC 3 loci because the frequency of IMA5 markers varied from $10 \%$ to $86 \%$ while most of the MFC6 and MFC3 alleles (14 among 22 alleles) were $<6 \%$. Seven combinations of primers and/or loci were tested according to their discriminating power in order to identify the most efficient combination for genotype discrimination. Starting with the most discriminating, one or several primers were added for each successive combination. Combination n ${ }^{\circ}$ 5(IMA5 + MFC6 + IMA9 + UBC841 + MFC3) discriminated all genotypes except two [IMA8-350 for 'Bioudi' (64-2218)/‘Ournakssi' (5-2282) andIMA12-580 for 'Bousbati' (2-2880)/ 'Ournakssi' (6-2214)] with the probability of obtaining a given genotype $<10^{-2}$

Identity of cultivars. In three cases, 'Abiarous' (65-3015), 'Bouankirh' (98-2397), and 'El Khal' (84-2283), two replicate trees of the same accession had different genotypes, which indicates they were mislabeled (Table 3). For 'Abiarous' (65-3015), the genotype of one of the trees corresponded to the accession labeled 'Chbaa Ou Rgoud' (10-2249). In two other cases, different accessions with the same 


\begin{tabular}{|c|c|c|c|c|c|c|}
\hline Primer & Sequence $\left(5^{\prime}-3^{\prime}\right)$ & $\begin{array}{c}\text { Expected } \\
\text { heterozygosity }\end{array}$ & $\begin{array}{c}\text { Observed } \\
\text { heterozygosity }\end{array}$ & $\begin{array}{l}\text { Markers } \\
\text { (no.) }\end{array}$ & $\begin{array}{c}\text { Molecular } \\
\text { profiles (no.) }\end{array}$ & $\begin{array}{c}\text { Dicriminating } \\
\text { power (D) }\end{array}$ \\
\hline $\mathrm{IMA5}^{\mathrm{z}}$ & CACACACACACACACAGT & --- & --- & 8 & 25 & 0.944 \\
\hline \multirow[t]{2}{*}{ MFC6 $^{y}$} & AGGCTACTTCAGTGCTACA & & & & & \\
\hline & GCCATAAGTAATAAAAACC & 0.814 & 0.900 & 14 & 21 & 0.929 \\
\hline IMA9 $9^{z}$ & GAGAGAGAGAGAGAGACG & --- & --- & 5 & 16 & 0.924 \\
\hline $\mathrm{UBC} 41^{\mathrm{z}}$ & GAGAGAGAGAGAGAGA(CT)C(AG) & --- & --- & 5 & 13 & 0.873 \\
\hline \multirow[t]{2}{*}{$\mathrm{MFC}^{\mathrm{y}}$} & GATATTTTCATGTTTAGTTTG & & & & & \\
\hline & GAGGATAGACCAACAACAAC & 0.755 & $0.736^{* *}$ & 8 & 14 & 0.869 \\
\hline IMA $12^{z}$ & CACACACACACACACATG & --- & --- & 6 & 17 & 0.868 \\
\hline $\mathrm{UBC} 818^{\mathrm{z}}$ & CACACACACACACACAG & --- & --- & 4 & 10 & 0.838 \\
\hline \multirow[t]{2}{*}{$\mathrm{MFC}^{\mathrm{y}}$} & ACTAGACTGAAAAAACATTGC & & & & & \\
\hline & TGAGATTGAAAGGAAACGAG & 0.659 & $0.647^{*}$ & 4 & 8 & 0.812 \\
\hline IMA $8^{z}$ & GAGAGAGAGAGAGAGAGT & --- & --- & 3 & 6 & 0.738 \\
\hline \multirow[t]{2}{*}{$\mathrm{MFC}^{\mathrm{y}}$} & GCTTCCGATGCTGCTCTTA & & & & & \\
\hline & TCGGAGACTTTTGTTCAAT & 0.529 & $0.417^{*}$ & 6 & 10 & 0.712 \\
\hline IMA834 & AGAGAGAGAGAGAGAG(CT)T & --- & --- & 4 & 8 & 0.650 \\
\hline \multirow[t]{2}{*}{$\mathrm{MFC}_{4}{ }^{\mathrm{y}}$} & CCAAACTTTTAGATACAACTT & & & & & \\
\hline & TTTCTCAACATATTAACAGG & 0.470 & 0.486 & 3 & 4 & 0.623 \\
\hline \multirow[t]{2}{*}{$\mathrm{MFC7}^{\mathrm{y}}$} & CACAATCAAAATAGTTACCG & & & & & \\
\hline & AGCGAAGACAGTTACAAAGC & 0.364 & $0.157^{* *}$ & 3 & 6 & 0.516 \\
\hline IMA $303^{z}$ & $(\mathrm{AGT})(\mathrm{AGC})(\mathrm{AGT}) \mathrm{CACCACCACCACCAC}$ & --- & --- & 2 & 3 & 0.082 \\
\hline
\end{tabular}

\section{zISSR primers.}

${ }^{\mathrm{y} S S R}$ primers.

*,***Heterozygote deficiency significant at $P \leq 0.05$ or 0.01 , respectively.

denomination had different genotypes, and one of the genotypes (i.e., 'Bioudi' 1-2222 and 'Ournakssi' 5-2280) was identical to that of another accession (i.e., 'Jeld Elhmar' and 'Bousbati', respectively).

Several cases of homonymy were identified in 'Bioudi', 'Chaari', 'Hamra', 'Ournakssi', and 'Front d'eloued'(Tables 1 and 3). Pairwise comparisons showed that genotype pairs from the same denomination were differentiated by $12-28$ markers, except for three pairs distinguished by only one or two ISSR markers and no SSR markers (Table 3). There were also 11 accession pairs from the same SSR genotype distinguished by only 1 to 3 ISSR markers (Table 3 ).

SSR and ISSR analyses enabled us to classify the germplasm into 52 molecular profiles corresponding to 46 well-defined cultivars and 6 caprifigs (Table 1). Variety assignation was unclear in the 20 remaining due to either mislabelling or homonymy.

Relationships among fig genotypes. Pairwise similarity among the 72 genotypes varied from 0.114 to 0.967 with an average of $0.415 \pm$ 0.108 . Phenetic analysis showed four clusters, A, B, C, and D, which included 4, 4, 2, and 62 genotypes, respectively (see Fig. 2 at the following website: http://cbnm.free.fr/Docs_divers/figuiers.doc). Pair-wise similarity among the 8 caprifig clones (in cluster D) varied from 0.406 for 'Front d'eloued C11'/'Front d'eloued C13' to 0.737 for 'Kasbat Skhirat'/'Ouzidane C18' with an average of $0.575 \pm 0.090$. Among caprifig clones, 'Amzin', 'Front d'eloued C11', and 'Front d'eloued C13' were the most similar, genetically, to cultivars 'Hamra' (352588), 'Reggoudi' (16-2895), and 'Arouchi' (85-2220); pair-wise similarity values among these clones were $0.357,0.344$, and 0.379 , respectively. Accessions 'Chbaa Ou Rgoud' (10-2249), 'El Hmiri' (88-2224), and 'Tameriout' (67-2400) (in clusters B and C) contained specific markers. Some accessions under the same denomination were very similar, including 'Bioudi' (64-2218)/'Bioudi' (1-2222),
'Ournakssi'(3-2280)/ 'Ournakssi'(6-2214), and 'Rhoudane' (24-2223)/ 'Rhoudane' (25-2227) (Table 3; also see Fig. 2 at http://cbnm.free. fr/Docs_divers/figuiers.doc).

\section{Discussion}

SSR and ISSR markers are reliable and complementary tools for fig characterization (Khadari et al., 2003c). Using these markers, five cases of mislabelling were found among 72 Moroccan fig accessions; three occurred within accessions 'Abiarous' (65-3015), 'Bouankirh' (98-2397), and 'El Khal' (84-2283) in which two trees were analyzed for each accession. However, since only one tree from other accessions was analyzed, we cannot exclude the possibility of other mislabelled accessions. Among the genotypes, the identities of 20 remain uncertain (in terms of denomination) due to mislabelling or homonymy.

With the exception of three pairs of acces- sions, distinct fig genotypes under the same denomination were clearly distinguished in the present study. For example, four of five accessions with 'Bioudi' denomination were differentiated by 12 to 28 markers and belonged to different genetic clusters. These four accessions were also identified as different genotypes using pomological descriptors such as skin color, fruit and fruit stalk shape, ostiole size, and skin cracks (Oukabli et al., 2003). In contrast, no pomological differences were observed among the following three pairs of accessions distinguished by only 1 to 2 ISSR markers: 'Bioudi'(64-2218)/ 'Bioudi' (1-2222), 'Ournakssi' (6-2214)/ 'Ournakssi' (3-2280), and 'Rhoudane' (24-2223)/ 'Rhoudane' (25-2227) (Table 3). Validity of discriminating ISSR markers, which were present in several other fig genotypes, was verified by repeating the amplifications and molecular analysis three times. These results strongly suggest that each of these pairs corresponds to a single original clone and that 1 or 2 distinct

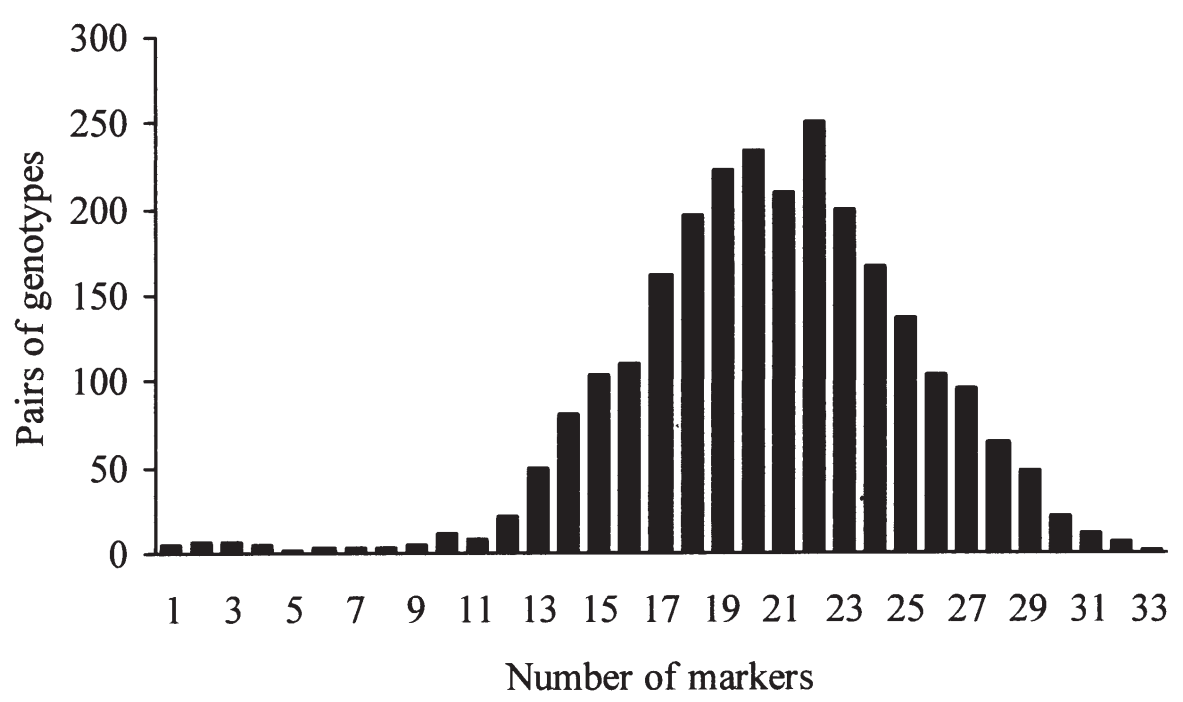

Fig. 1. Frequency distribution of genetic dissimilarity for all pairwise combinations among 72 Moroccan fig genotypes. 
Table 3. Number of genetic differences between accessions of the same denomination (upper part of the table) or the same SSR genotype (lower part of the table).

\begin{tabular}{|c|c|c|c|}
\hline \multicolumn{2}{|c|}{ Comparison } & \multicolumn{2}{|c|}{ Markers $^{\mathrm{z}}$ (no.) } \\
\hline Accession 1 & Accession 2 & SSR & ISSR \\
\hline Abiarous $^{y}(65-3015$, tree $9-8)$ & Abiarous $^{\mathrm{y}}(65-3015$, tree 9-9) & 7 & 14 \\
\hline Bioudi (64-2218) & Bioudi (61-2255) & 7 & 12 \\
\hline Bioudi (64-2218) & Bioudi (53-2878) & 6 & 16 \\
\hline Bioudi (64-2218) & Bioudi (66-2258) & 10 & 13 \\
\hline Bioudi (64-2218) & Bioudi (1-2222) & 0 & 2 \\
\hline Bioudi (61-2255) & Bioudi (53-2878) & 10 & 14 \\
\hline Bioudi (61-2255) & Bioudi (66-2258) & 9 & 14 \\
\hline Bioudi (61-2255) & Bioudi (1-2222) & 7 & 10 \\
\hline Bioudi (53-2878) & Bioudi (66-2258) & 12 & 13 \\
\hline Bioudi (53-2878) & Bioudi (1-2222) & 6 & 16 \\
\hline Bioudi (66-2258) & Bioudi (1-2222) & 10 & 13 \\
\hline Bouankirh $^{\mathrm{y}}(98-2397$, tree 2-4) & Bouankirh $^{\mathrm{y}}(98-2397$, tree $2-5)$ & 7 & 12 \\
\hline Chaari (95-2881) & Chaari $(96-2587)$ & 5 & 9 \\
\hline El Khal' ${ }^{\mathrm{y}}(84-2283$, tree $11-1)$ & El Khal' ${ }^{y}(84-2283$, tree $11-3)$ & 9 & 19 \\
\hline Hamra $(35-2588)$ & Hamra $(22-2225)$ & 5 & 7 \\
\hline Hamra (35-2588) & Hamra (86-2252) & 6 & 8 \\
\hline Hamra (22-2225) & Hamra (86-2252) & 10 & 11 \\
\hline Ournakssi (5-2282) & Ournakssi (6-2214) & 8 & 11 \\
\hline Ournakssi (5-2282) & Ournakssi (3-2280) & 8 & 10 \\
\hline Ournakssi (6-2214) & Ournakssi (3-2280) & 0 & 1 \\
\hline Rhoudane (24-2223) & Rhoudane (25-2227) & 0 & 2 \\
\hline Front d'eloued C11 & Front d'eloued C13 & 7 & 6 \\
\hline Amtalaa Aarch $(87-2210)^{x}$ & Abouharchaou $(71-2395)^{x}$ & 0 & 1 \\
\hline Ournakssi (5-2282) & Bioudi (64-2218) & 0 & 1 \\
\hline Ournakssi (5-2282) & Bioudi (1-2222) & 0 & 1 \\
\hline Tarlit $(68-2398)^{x}$ & El Har $(59-2261)^{x}$ & 0 & 1 \\
\hline Arouchi $(85-2220)^{x}$ & Abrouki $(90-2221)^{x}$ & 0 & 2 \\
\hline Bioudi (1-2222) & Ferzaoui $(93-2289)^{x}$ & 0 & 2 \\
\hline Noukali $(31-2254)^{x}$ & Hamra $(22-2252)$ & 0 & 2 \\
\hline Rhoudane (24-2223) & Aounq El Hmam $(94-2876)^{x}$ & 0 & 2 \\
\hline El quoti Lezreq $(62-2883)^{x}$ & Azougouar $(102-2116)^{x}$ & 0 & 3 \\
\hline Hamra (86-2252) & El Khal (84-2283, tree 11-1) & 0 & 3 \\
\hline Ournakssi (5-2282) & Ferzaoui $(93-2289)^{x}$ & 0 & 3 \\
\hline
\end{tabular}

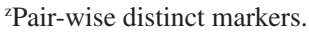

y Considered mislabeled.

xPair-wise accessions considered as a single original clone.

ISSR bands correspond to somatic mutations, which may indicate ancient cultivars. Indeed, the minor mode observed in the distribution of genetic differences in pair-wise comparisons would also indicate somatic variation within clones (Fig. 1). This explanation may also apply to the 11 accession pairs distinguished by only 1 to 3 ISSR bands, which led to misclassification of 12 out of 46 previously defined cultivars (Tables 1 and 3). However, due to distinctive pomological characteristics (Oukabli et al., 2003), characterization must be validated with more SSR loci in order to verify that each pair of accessions originate from a single clone.

The original sampling scheme of the Moroccan germplasm appears to have followed a policy of a single introduction for highly localized, apparently homogeneous, cultivar denominations, as well as several introductions for more widespread denominations. Our results show that 1) large diversity in cultivar names corresponds to large genetic diversity and 2) variety names that have broader diffusion correspond to several unrelated and pomologically-distinct genotypes. Thus, it appears that Moroccan cultivars are generally highly local.

To choose a genotype as a reference genotype, we propose the following rule for monoclonal cultivars: when several fig trees grouped under the same denomination have similar morphological characteristics, originate from different collections, nurseries, and orchards, and display the same molecular pattern, they shsould be considered as a reference genotype for the cultivar. This rule was proposed by Khadari et al. (2003a) to establish reference genotypes for olive germplasm in France. Conversely, choosing one or several genotypes as reference for a genetically heterogeneous cultivar should also take into account discriminative pomological traits, as well as the relative importance of cultivation among the clones.

The present study provides the first molecular database for Moroccan fig germplasm management. Among 50 fig cultivars examined (46 welldefined and four genetically heterogeneous), the germplasm displayed diverse plant material and appears to represent a major component of the Moroccan fig genetic resources. Future collection and introductions must include molecular analysis in order to optimise the genetic diversity of the germplasm and avoid duplications observed in the present collection.

\section{Literature Cited}

Belkhir, K. 1999. Genetix, version 4.0. A Windows program for population genetics analysis. Laboratoire Génome, Populations, Interactions. CNRS UPR 9060, Université Montpellier II, Montpellier, France.

Chessa,I., G. Nieddu, andP. Serra 1998. Fig germplasm characterization using isozyme analysis. ActaHort. 480:143-148.

DeMasi,L.,M.Cipollaro,G.DiBernardo,U.Galderesi,
G. Galano, A. Cascino, G. Grassi, E. Pavone, and A. Simeone 2003. Clonal selection and molecular characterization by RAPD analysis of the fig ( $\mathrm{Fi}$ cus carica L.) 'Dottato' and 'Bianco del Cilento' cultivars in Italy. Acta Hort. 605:65-68.

Elisiario, P.J., M.C. Neto, L.F. Cabrita, and J.M. Leitao 1998. Isozyme and RAPDs characterisation of a collection of fig (Ficus carica L.) traditional varieties. Acta Hort. 480:149-154.

Geuna, F., M. Toschi, and D. Bassi. 2003. The use of AFLP markers for cultivar identification in apricot. Plant Breeding 122:526-531.

Hokanson, S.C., W.F. Lamboy, A.K. Szewc-McFadden, and J.R. McFerson. 2001. Microsatellite(SSR) variation in a collection of Malus (apple) species and hybrids. Euphytica 118:281-294.

Jones, C.J., K.J. Edwards, and S. Castaglione. 1997. Reproductibility testing of RAPD, AFLP and SSR markers in plants by a network of European laboratories. Mol. Breeding 3:381-390.

Khadari, B., Ph. Lashermes, and F. Kjellberg. 1995 RAPD fingerprints for identification and genetic characterization of fig (Ficus carica L.) genotypes. J. Genet. Breeding 49:77-86.

Khadari, B.,I.Hochu, S. Santoni, andF. Kjellberg. 2001 Identification and characterisation of microsatellite loci in the common fig (Ficus carica L.) and representative species of genus Ficus. Mol. Ecol. Notes 1:191-193.

Khadari, B., C. Breton, N. Moutier, J.P. Roger, G. Besnard, A. Bervillé, and F. Dosba. 2003a. The use of molecular markers for germplasm management in French olive collection. Theor. Appl. Genet. 106:521-529.

Khadari, B., I.Hochu, L. Bouzid, S. Santoni, J.P. Roger, and F. Kjellberg. 2003b. The use of microsatellite markers for identification and genetic diversity evaluation of the fig collection in CBNMP. Acta Hort. 605:77-86.

Khadari, B., I. Hochu, S. Santoni, A. Oukabli, M. Ater, J.P. Roger, andF. Kjellberg. 2003c. Which molecular markers are best suited to identify fig cultivars: A comparison of RAPD, ISSR and microsatellite markers. Acta Hort. 605:69-75.

Nei, M. 1978. Estimation of average heterozygosity and genetic distances from a small number of individuals. Genetics 89:583-590.

Oukabli, A., A. Mamouni, M. Laghezali, B. Khadari, J.P. Roger, F. Kjellberg, and M.Ater. 2003. Genetic variability in Moroccan fig cultivars (Ficus carica L.) based on morphological and pomological data. Acta Hort. 605:311-318.

Oraguzie, N.C., S.E. Gardiner, H.C.M. Heather, M. Stefanati, R.D. Ball, V.G.M. Vincent, and A.G. white 2001. Genetic diversity and relationships in Malus sp. Germplasm collections as determined by randomly amplified polymorphic DNA. J. Amer. Soc. Hort. Sci. 126:318-328.

Raymond, M. and F. Rousset. 1995. An exact test for population differentiation. Evolution 49:1280-1283

Tessier, C., J. David, P. This, J.M. Boursiquot, and A. Charrier 1999. Optimization of the choice of molecularmarkers for varietal identification in Vitis vinifera L. Theor. Appl. Genet. 98: 171-177.

Uzum, H.I., I. Polat, and S. Gözlekci. 2003. Molecular identification of Turkish fig cultivars by fruit and leaf isozymes. Acta Hort. 605:45-50.

Valizadeh, M., P. Rivals and G. Valdeyron 1977. Utilisation du polymorphisme protéique pour l'étude des variétés de figuier (Ficus carica $\mathrm{L}$.) C.R. Acad. Agr. 63:647-655.

Wünsch, A. and J.I. Hormaza. 2002. Cultivar identification and genetic fingerprinting of temperate fruit tree species using DNA markers. Euphytica 125:59-67.

Zohary, D. and M.Hopf. 2000. Domestication of plants in the Old World. 3rd ed. Oxford, Univ. Press. 